\title{
Is macrocytic erythrocyte a new prognostic parameter in critical COVID-19 disease?
}

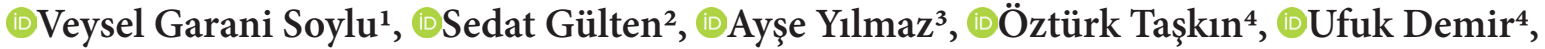 \\ (D) Funda İnan Çatan 5 \\ ${ }^{1}$ Kastamonu University Faculty of Medicine, Department of Intensive Care Medicine, Kastamonu, Turkey \\ ${ }^{2}$ Kastamonu University Faculty of Medicine, Department of Medical Biochemistry, Kastamonu, Turkey \\ ${ }^{3}$ Kastamonu Training and Research Hospital, Department of Anesthesiology and Intensive Care Medicine, Kastamonu, Turkey \\ ${ }^{4}$ Kastamonu University Faculty of Medicine, Department of Anesthesiology and Intensive Care Medicine, Kastamonu, Turkey \\ ${ }^{5}$ Kastamonu University Faculty of Medicine, Department of Biostatistics, Kastamonu, Turkey
}

Cite this article as: Soylu VG, Gülten S, Yllmaz A, Taşkın Ö, Demir U, İnan Çatan F. Is macrocytic erythrocyte a new prognostic parameter in critical COVID-19 disease?. J Health Sci Med 2021; 4(6): 828-834.

\begin{abstract}
Introduction: In critical COVID- 19 patients, we aimed to examine the relationship mortality between the parameters and the macrocytic/microcytic erythrocyte population that are routinely evaluated in each patient admitted to the intensive care unit.

Material and Method: It is a retrospective cross-sectional study and was conducted in Kastamonu University, Faculty of Medicine, a tertiary hospital intensive care units located in the North of Turkey .198 nonanemic critical COVID-19 patients treated between November 2020 and February 2021 were evaluated. The patients were divided into two groups as survival and non survival. APACHE II score, SAPS II score and routine blood examinations of the patients were evaluated.

Results: Among the groups; APACHE II score ( $p<0.001)$, SAPS II score $(p<0.001)$, CRP $(p<0.001)$, ferritin $(p<0.001)$, d-dimer $(\mathrm{p}<0.001)$, platelet distribution width $(\mathrm{p}<0.009)$, mean platelet volume $(\mathrm{p}=0.005)$ and large platelet ratio $(\mathrm{p}=0.02)$ values were higher, platelet counts $(\mathrm{p}=0.02)$ were lower, and these parameters were statistically significant between the two groups. There was no difference in erythrocyte distribution volume and microcytic erythrocyte percentage between the groups, but according to the cox regression analysis, each unit increase in macrocytic erythrocyte percentage was associated with a 1.203fold increase in mortality.

Conclusion: Routine procedures performed in every patient admitted to the intensive care unit can provide information about mortality. Macrocytic erythrocyte percentage, which is not generally considered in non-anemic patients, may be a new marker for mortality.
\end{abstract}

Keywords: Macrocytic erythrocyte population, intensive care unit, COVID-19, complete blood count, mortality

\section{INTRODUCTION}

The coronavirus disease emerged in the human population in late December 2019 and spread all over the world, and was declared a pandemic by the World Health Organization (WHO) on March 11, 2020 (12 ). Although vaccination studies have started in many countries for COVID-19 disease, this disease still continues worldwide with all its severity. In the literature, it has been stated that the intensive care mortality associated with COVID-19 disease is between $40 \%$ and $90 \%$ (3). Since the beginning of the pandemic; a lot of research has been done to predict the intensive care prognosis and mortality of critical COVID-19 patients. In these studies, some scoring (4), tomography findings (5) and inflammatory markers (6-7) were associated with the intensive care prognosis and mortality of critically ill COVID-19 patients. Acute Physiology and Chronic Health Evaluatioon Score II (APACHE II), Simplified Acute Physiology Score II (SAPS II) and blood tests are used in the routine evaluation of patients in both COVID intensive care unit and non COVID intensive care unit admission. Complete blood count provides vital parameters that guide clinical management, including diagnosis, infection or inflammation, anemia, response to treatment, pathogenesis, and inflammatory process (8). 
The aim of every patient admitted to the ICU is to reduce mortality and morbidity. The markers that guide us in this regard are very important. $\mathrm{CBC}$, which is among the routine tests, has parameters such as lymphocyte count, platelet count, red cell distribution width, etc. that can be associated with mortality in COVID and nonCOVID ICU patients. These parameters are not only correlated with adverse outcomes of COVID-19 disease, but may also be associated with bone marrow suppression due to malignancy or with previously diagnosed anemia.

Macrocytic erythrocyte populations (Macro R) and microcytic erythrocyte populations (Micro R) are routinely studied parameters in the $\mathrm{CBC}$ test. These parameters are used to investigate possible causes of anemia (9). However, these parameters are generally not considered in patients who are not anemic.

In critically COVID-19 patients, we evaluated APACHE II , SAPS II, whole blood tests and Macro R/ Micro R, which are routinely used in the evaluation of every patients admitted to the intensive care unit. We aimed to investigate the relationship between this parameters and prognosis or mortality of patients in intensive care units .

\section{MATERIAL AND METHOD}

Approval for study was obtained from the Noninterventional Clinical Researchs Ethics Committee of Kastamonu University Faculty of Medicine (Date: 25/02/2021, Decision No: KAEK-2020-143-38). All procedures were carried out in accordance with the ethical rules and the principles of the Declaration of Helsinki.

It is a retrospective cross-sectional study and was conducted in Kastamonu University, Faculty of Medicine, a tertiary hospital intensive care units located in the North of Turkey. In the study, 236 critical COVID-19 patients treated in the third level COVID intensive care unit between November 2020 and February 2021 were evaluated. For a more objective evaluation of CBC parameters; as inclusion criteria for the study; not having any previous diagnosis of malignancy and anemia defined by the World Health Organization (hemoglobin concentration below $12 \mathrm{~g} / \mathrm{dL}$ in women and $13 \mathrm{~g} / \mathrm{dL}$ in men) (10). Thirteen patients with a history of malignancy and 25 patients with anemia were excluded from the study, and 198 patients were included in the study. All of the patients included in the study were critical COVID-19 patients according to the COVID-19 Adult Patient Management Guidelines published by the Ministry of Health of the Republic of Turkey (11). All of the patients included in the study were positive in the realtime polymerase chain reaction (RT-PCR) test performed by the hospital laboratory. Patients who were successfully treated and transferred to the service during the intensive care treatment process were named Survival Group (98 patients) and those who died were named Non- survival Group (100 patients). The medical records and electronic patient data system of the patients included in the study were reviewed retrospectively. Patients; Age, gender, APACHE II scores, SAPS II scores, ferritin, C-reactive protein (CRP), procalcitonin, d-dimer values and 27 parameter $\mathrm{CBC}$ values were recorded on the first day of admission to the intensive care unit. . CBC parameters were calculated using an automated hematology analyzer (XN-1000-Hematology-analyzer-Sysmex Corporation, Japan).

\section{Statistical Analysis}

The significance in differences between the means of two continuous and normally distributed variables was determined by independent t-test. Non-normal distributed continuous variables were explained by Mann-Whitney U test. Pearson's chi-square test was conducted to determine the relationship in proportions of categorical variables between two groups. The optimal cut-off values of continuous Apache and Saps score were calculated by applying the Receiver Operating Curve (ROC9 analysis. The association of biochemical parameters with survival was determined by Cox regression analysis. Cox regression with forward stepwise method was used to determine the impacts of age, gender, and other important biochemical variables. Relative risk was calculated with hazard risk and $95 \%$ confidence interval (CI). $\mathrm{p}<0.05$ was considered as statistically significant. All statistical analyses were performed using the SPSS 23.00 (SPSS Inc, Chicago, USA).

\section{RESULTS}

A total of 198 patients were included in the study. Of the participants, $67(33.8 \%)$ were female and $131(66.2 \%)$ were male. After intensive care treatment, 98 (49.5\%) patients were transferred to the service (Survival Group); $100(50.5 \%)$ patients died during the intensive care treatment process (Non- survival Group).

Sixty-two (63.2\%) patients in Survival Group and sixtynine (69\%) patients in Non- survival Group were male. The patients included in the study were between the ages of 40-98 and the mean age of patients was $67.05 \pm 0.47$. In the data analysis made between the groups; the mean age of the patients in Non- survival Group (68.75 \pm 8.98$)$ was higher than the mean age of the surviving patients (65.31 \pm 11.79$)$.

The patients in Non- survival Group ; age, APACHE II score, SAPS II score, CRP, ferritin, d-dimer, platelet distribution width (PDW), mean platelet volume (MPV) and large platelet ratio (\%P-LCR) were higher on the first day of admission to the intensive care unit, but 
platelet(PLT) counts were lower than Survival Group

There were statistically significant differences in these parameters between both groups (Age $(\mathrm{P}<0.02)$, APACHE II $(\mathrm{P}<0.001)$, SAPS II $(\mathrm{P}<0.001)$, Crp ( $<0.001)$, Ferritin $(\mathrm{P}<0.001)$, D -dimer $(\mathrm{P}<0.001)$, Plt $(\mathrm{P}=$ 0.02), PDW ( $\mathrm{P}=0.009)$, MPV $(\mathrm{P}=0.005)$ and \% P-LCR $(\mathrm{P}=0.002))$. Red cell distribution width $(\% \mathrm{RDW})$ values were similar between both groups; There was no statistical difference between the groups. ( $\% \mathrm{RDW}(\mathrm{P}=$ 0.56)) (Table 1)

Cox regression analysis with stepwise method was used to analyze the risk factors for fatal outcomes in patients with COVID -19. The significant parameters were entered the Cox model to identify independent predictors of death. Model performed well regarding the result of omnibus test. The results of this test explained that our model is significant $(\mathrm{X} 2=60.75, \mathrm{P}<0.001)$ improvement in fit relative to null. Biochemical variables including Saps II (HR 1.110, CI 1.076-1.146, $\mathrm{P}<0.001$ ), D-dimer (HR 0.873, CI 0.784-0.973, $\mathrm{P}=0.014$ ), Procalcitonin (HR 0.877, CI 0.773-0.994, $\mathrm{P}=0.04$ ), MONO\% (HR 0.902, CI 0.845-0.963, $\mathrm{P}=0.002$ ) and MacroR (\%) (HR 1.203, CI 1.058-1.369, $\mathrm{P}=0.005)$ were predictive of fatal outcomes. A one-unit increase in MacroR was associated with a 1.203 -fold increase in mortality and was considered a major predictor. An increase in Saps II score was also associated with mortality. Each unit increase in Saps II score was associated with a 1.11-fold increase in mortality rate (Table 2).

\begin{tabular}{|c|c|c|c|c|c|}
\hline Variables & $\begin{array}{c}\text { Total } \\
\mathrm{n}=198 \mathrm{M}^{*} \pm \mathrm{SD}\end{array}$ & $\begin{array}{c}\text { Survival Group } \\
n=98 M \pm S D\end{array}$ & $\begin{array}{c}\text { Non- survival Group } \\
n=100 \mathrm{M} \pm \mathrm{SD}\end{array}$ & test & $\mathbf{P}$ \\
\hline Age (years) & $67.05 \pm 0.47$ & $65.31 \pm 11.79$ & $68.75 \pm 8.98$ & $\mathrm{t}=-2.30$ & 0.02 \\
\hline Gender & 198 & $62 / 36^{\star *}$ & $69 / 31^{* *}$ & $\mathrm{X} 2=0.72$ & 0.39 \\
\hline Apache II & $22.41 \pm 7.82$ & $16.56 \pm 5.31$ & $28.14 \pm 5.20$ & $\mathrm{t}=--15.48$ & $<0.001$ \\
\hline Saps II & $30.69 \pm 9.54$ & $23.42 \pm 5.89$ & $37.81 \pm 6.60$ & $t=-16.16$ & $<0.001$ \\
\hline Ferritin (ng/ml) & $909.32 \pm 454.58$ & $690.28 \pm 443.31$ & $1123.98 \pm 353.00$ & $\mathrm{t}=--7.60$ & $<0.001$ \\
\hline D Dimer (mg/l) & $2.60 \pm 2.04$ & $1.95 \pm 1.65$ & $3.23 \pm 2.20$ & $t=--4.61$ & $<0.001$ \\
\hline Procalcitonin (mg/dl) & $1.61 \pm 1.88$ & $103.99^{*}$ & $95.10^{*}$ & $Z=-1.10$ & 0.27 \\
\hline $\mathrm{WBC}\left(10^{3} / \mathrm{uL}\right)$ & $10.12 \pm 5.35$ & $10.20 \pm 5.19$ & $10.04 \pm 5.53$ & $\mathrm{t}=-0.21$ & 0.83 \\
\hline $\mathrm{RBC}\left(10^{6} / \mathrm{uL}\right)$ & $4.47 \pm 0.80$ & $102.67^{\star}$ & $96.40^{*}$ & $Z=-0.77$ & 0.44 \\
\hline $\mathrm{HGB}(\mathrm{g} / \mathrm{dL})$ & $14.54 \pm 2.14$ & $98.66^{*}$ & $100.32^{*}$ & $Z=-0.20$ & 0.83 \\
\hline $\mathrm{MCV}(\mathrm{fL})$ & $85.88 \pm 6.82$ & $85.81 \pm 7.19$ & $85.95 \pm 6.48$ & $\mathrm{t}=--0.14$ & 0.88 \\
\hline $\mathrm{MCH}(\mathrm{pg})$ & $28.89 \pm 11.25$ & $95.51^{\star}$ & $103.42^{\star}$ & $Z=-0.97$ & 0.33 \\
\hline $\mathrm{MCHC}(\mathrm{g} / \mathrm{dL})$ & $33.46 \pm 10.16$ & $96.21^{\star}$ & $102.72^{\star}$ & $Z=-0.79$ & 0.42 \\
\hline $\operatorname{PLT}\left(10^{3} / \mathrm{uL}\right)$ & $205.42 \pm 92.01$ & $108.54^{\star}$ & $90.65^{*}$ & $Z=-2.19$ & 0.02 \\
\hline RDW-SD (fL) & $45.39 \pm 6.87$ & $44.86 \pm 5.96$ & $45.91 \pm 7.66$ & $\mathrm{t}=--1.07$ & 0.28 \\
\hline RDW-CV (\%) & $14.63 \pm 2.53$ & $97.11^{\star}$ & $101.85^{\star}$ & $Z=-0.58$ & 0.56 \\
\hline PDW (fL) & $12.11 \pm 2.26$ & $11.69 \pm 2.00$ & $12.52 \pm 2.42$ & $t=--2.62$ & 0.009 \\
\hline MPV (fL) & $10.54 \pm 0.95$ & $10.35 \pm 0.87$ & $10.73 \pm 1.00$ & $\mathrm{t}=--2.87$ & 0.005 \\
\hline P-LCR (\%) & $29.10 \pm 7.30$ & $27.52 \pm 6.65$ & $30.65 \pm 7.60$ & $\mathrm{t}=--3.08$ & 0.002 \\
\hline NRBC\# $\left(10^{3} / \mathrm{uL}\right)$ & $0.02 \pm 0.09$ & $93.35^{\star}$ & $105.53^{\star}$ & $Z=-1.83$ & 0.06 \\
\hline NRBC\% (\%) & $0.16 \pm 0.70$ & $94.21^{\star}$ & $104.68^{*}$ & $Z=-1.62$ & 0.10 \\
\hline NEUT\# $\left(10^{3} / \mathrm{uL}\right)$ & $8.46 \pm 5.08$ & $8.47 \pm 4.96$ & $8.44 \pm 5.22$ & $\mathrm{t}=0.04$ & 0.96 \\
\hline LYMPH\# $\left(10^{3} / \mathrm{uL}\right)$ & $1.08 \pm 0.79$ & $101.20^{*}$ & $97.84^{\star}$ & $Z=-0.41$ & 0.68 \\
\hline $\mathrm{EO} \#\left(10^{3} / \mathrm{uL}\right)$ & $0.04 \pm 0.12$ & $102.24^{\star}$ & $96.71^{\star}$ & $Z=-0.69$ & 0.48 \\
\hline BASO\# $\left(10^{3} / \mathrm{uL}\right)$ & $0.03 \pm 0.03$ & $0.03 \pm 0.2$ & $0.03 \pm 0.02$ & $\mathrm{t}=0.21$ & 0.83 \\
\hline NEUT\% (\%) & $81.01 \pm 10.97$ & $80.48 \pm 11.69$ & $81.51 \pm 10.25$ & $t=-0.66$ & 0.51 \\
\hline LYMPH\% (\%) & $12.87 \pm 9.22$ & $99.31^{*}$ & $99.69^{*}$ & $Z=-0.05$ & 0.96 \\
\hline MONO\% (\%) & $5.39 \pm 3.12$ & $5.51 \pm 3.20$ & $5.28 \pm 3.05$ & $\mathrm{t}=0.51$ & 0.61 \\
\hline $\mathrm{EO} \%(\%)$ & $0.41 \pm 1.24$ & $102.57^{\star}$ & $96.49^{*}$ & $Z=-0.78$ & 0.43 \\
\hline BASO\% (\%) & $0.31 \pm 0.22$ & $200.30^{*}$ & $98.72^{*}$ & $Z=-0.19$ & 0.84 \\
\hline MicroR (\%) & $5.22 \pm 6.47$ & $99.88^{\star}$ & $99.13^{*}$ & $Z=-0.09$ & 0.92 \\
\hline MacroR (\%) & $4.09 \pm 1.35$ & $96.84^{*}$ & $102.11^{\star}$ & $Z=-0.64$ & 0.51 \\
\hline
\end{tabular}


Table 2. Cox regression analysis for prognostic factors

\begin{tabular}{|c|c|c|c|c|c|c|}
\hline \multirow{2}{*}{ Variables } & \multirow{2}{*}{ B } & \multirow{2}{*}{ SE } & \multirow{2}{*}{$\mathbf{p}$} & \multirow{2}{*}{ HR } & \multicolumn{2}{|c|}{ 95\% CI for $\mathrm{HR}$} \\
\hline & & & & & Lower & Upper \\
\hline Saps II & 0.105 & 0.016 & $<0.001$ & 1.110 & 1.076 & 1.146 \\
\hline D-Dimer & -0.135 & 0.055 & 0.014 & 0.873 & 0.784 & 0.973 \\
\hline Procalcitonın & -0.131 & 0.064 & 0.040 & 0.877 & 0.773 & 0.994 \\
\hline MONO\%(\%) & -0.103 & 0.033 & 0.002 & 0.902 & 0.845 & 0.963 \\
\hline MacroR(\%) & 0.185 & 0.066 & 0.005 & 1.203 & 1.058 & 1.369 \\
\hline
\end{tabular}

The optimal cut-off values of Apache II and Saps II parameters were calculated by the ROC analysis (Figure 1). Areas under the curve (AUC) of Apache II and Saps II were 0.928 and 0.944 , respectively (Table 3 ). They were the potential mortality biomarkers. The sensitivity and specificity were 0.86 and 0.898 for Apache II , and 0.85 and 0.918 for Saps II . In addition to this, the optimal cutoff values of Apache II and Saps II were 22.50 and 30.50, respectively.

Table 3. Areas under the curve (AUC) of Apache II and Saps II variables

\begin{tabular}{|lccccc|}
\hline \multirow{2}{*}{ Variables } & Area & SE & $\begin{array}{c}\text { Asymptotic } \\
\text { Sig. }\end{array}$ & \multicolumn{2}{c|}{$\begin{array}{c}\text { Asymptotic } \\
\text { 95\% CI }\end{array}$} \\
\cline { 3 - 6 } & & & Lower & Upper \\
\hline Apache II & 0.928 & 0.019 & $<0.001$ & 0.892 & 0.965 \\
Saps II & 0.944 & 0.016 & $<0.001$ & 0.912 & 0.975 \\
\hline $\begin{array}{l}\text { Abbreviations: APACHE II: Acute Physiology and Chronic Health Assessment Score } \\
\text { II,SAPS II: Simplified Acute Physiology Score II }\end{array}$ \\
\hline
\end{tabular}

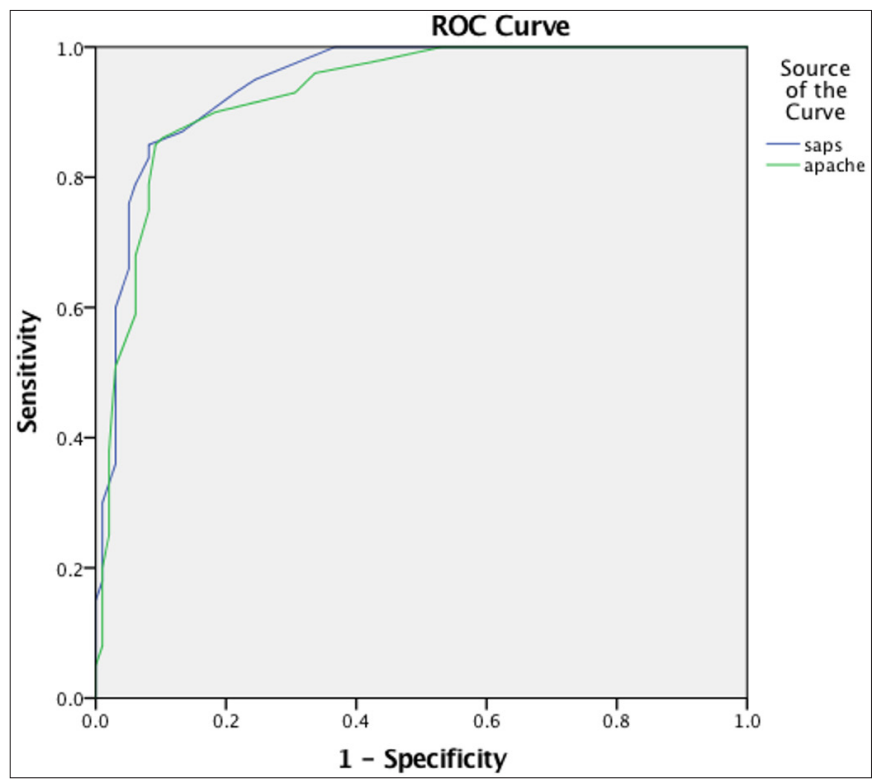

Figure 1. ROC curve of Apache II and Saps II variables

\section{DISCUSSION}

Our study revealed that age, APACHE II score, SAPS II score, CRP, ferritin, D-dimer and CBC parameters plt, MPV, PDW, \%P-LCR values were statistically significant between surviving and non-surviving patients in critical COVID-19 patients. These findings were similar to previous studies (12-13). Contrary to the findings in the literature, the \%RDW values were not statistically different in our study between surviving and nonsurviving patients (14). There are few studies on the \%Macro $\mathrm{R}$ value in the literature. Our study revealed the relationship of increased macro $\mathrm{R}$ values with mortality in critical COVID-19 disease, according to the results of the cox regression analysis performed in addition to other studies in the literature. With these results, according to the roc analysis for APACHE II and SAPS II scores; both scores were found to have high sensitivity and specify.

The male patient population is higher among patients treated in intensive care units due to COVID-19 disease. In our study, $66.1 \%$ of the total number of patients was male, which was similar to the studies in the literature (12-15). According to the meta-analysis published by Armstrong et al. (16), intensive care mortality in critical COVID-19 disease ranges from $34 \%$ to $49.7 \%$. In a study conducted with the participation of more than 17 million COVID-19 patients in England, it was stated that the male gender was 1.6 times more likely to face the risk of mortality compared to the female gender (17). In our study, we found that the ICU mortality was $50.5 \%$ and $69 \%$ of the patients with mortality were male.

APACHE II and SAPS II scores are important parameters used in the evaluation of prognosis in critically ill patients treated in the intensive care unit. In their study, Xie et al stated that the APACHE II score on the first day of admission to the intensive care unit is an independent risk factor for 28-day mortality in COVID-19 disease. In our study, we found that there was a statistically significant difference in the APACHE II score between patients who survived and died. However, in our study, the APACHE II median values of the patients in both groups were higher than the study by Xie et al. (18). In our study, APACHE II score cut-off value was calculated as 22.5 , sensitivity 0.86 and specificity 0.898 . This value was found to be consistent with the literature (19). Larcher et al. (20)revealed the relationship between SAPS II scoring and mortality in COVID-19 disease. Duclos et al. (21) found the cut-off value as 31 , sensitivity as 1 , and specificity as 0.58 for the SAPSII score in their study with critical COVID-19 patients. In our study, the SAPS II score was statistically significant between surviving and non-surviving patients, and the cut-off value was 
30.5 , the sensitivity 0.85 , and the specificity 0.918 . In addition, in the cox regression analysis, we found a 1.11 fold increase in mortality with each point increase in the SAPS II score.

CRP and ferritin markers are inflammatory markers; as stated in a meta-analysis including 83 studies in the literature, it is seen that CRP and ferritin values have a significant relationship with mortality in COVID-19 disease (22). Studies have shown that d dimer, which is one of the coagulopathy markers, is associated with mortality at high values in COVID-19 disease (23). In our study, the CRP, ferritin and dimer values of the patient group who died during the intensive care unit were higher and there was a statistically significant difference between the groups.

Complete blood count examination is an easily accessible and fast test. CBC examination is the most widely used first laboratory examination (24). There are studies in the literature that indicate the importance of $\mathrm{CBC}$ parameters about the prognosis of COVID-19 disease. In most of these studies, it was reported that there was a significant difference in neutrophil count, lymphocyte count, and platelet count between surviving and nonsurviving patients (25). Ouyang et al. (26) reported in their study that non-survival patients had lower platelet counts. In our study, there was no statistical difference between the lymphocyte count and neutrophil counts among the non-survival patients, while the non-survival patients had lower platelet counts and there was a statistically significant difference between the groups. MPV, PDW and \%P LCR; are some parameters related to platelet cells. In a study conducted with COVID-19 patients, the mean \% P LCR values were found to be $21.6 \%$ in surviving patients and $26.7 \%$ in non-survival patients. In our study, the mean \% P LCR values of the non-survival patients were higher and there was a statistically significant difference between the groups. In the study of Güçlü et al. (27) investigating the effect of COVID-19 disease on platelet count and indices, they stated that PDW and MPV values were higher in nonsurvival patients and there was a statistically significant difference. In our study non-survival patients had higher PDW and MPV values, and similar to this study, there was a statistically significant difference between the groups Thrombocytopenia is an expected finding in COVID-19 patients. Accordingly, as the platelet count decreases, there is an increase in platelet release from the bone marrow. This may explain the increase in MPV, PDWand P LCR.

Rdw is a parameter that reflects the degree of heterogeneity of erythrocyte volume used in the differential diagnosis of bone marrow dysfunction, iron deficiency anemia, and hematological system diseases. Proinflammatory state and hypoxia impair erythropoiesis and cause an increase in RDW. The studies have shown that RDW elevation is compatible with mortality in COVID-19 disease and in many disease groups (28). In the metaanalysis published by Lee et al. (29) in 2021; It was stated that $\mathrm{RDW}$ elevation was correlated with the negative outcomes of COVID-19 disease. However, the effect of anemia-independent RDW elevation in COVID-19 was not clarified in this study. In the study of Rapp et al. (14) with COVID-19 patients, it was revealed that RDW elevation was associated with mortality and morbidity, independent of anemia. However, patients who were not hospitalized were included in this study. The patients included in our study were patients who were not anemic and were treated in the intensive care unit. There was no statistically significant difference in RDW values between survivors and non-survivors.

\%Macro R and \%Micro R markers are parameters used to investigate possible causes in the etiology of anemia. Apart from investigating the etiology of anemia, they are not the most important markers for clinicians. There are limited publications in the literature stating that \%Macro $\mathrm{R}$ and \%Micro $\mathrm{R}$ values are associated with mortality. One of them was the study conducted by Horne et al (30). This study includes the patient group without COVID-19 disease. As a result of the cox regression analysis performed in our study, each unit increase in \% Macro R values in COVID-19 patients was found to be compatible with a 1.2-fold increase in mortality. However, the $\%$ micro $r$ value was not associated with mortality. There is an inflammatory state and a hypoxic process in COVID-19 disease (28). Depending on these factors, there is an increase in the release of erythropeitn. The increased secretion of erythropoietin causes the release of immature reticulocyte from the bone marrow into the circulation (31). Macrocytic erythrocytes are thought to be immature macrocytic reticulocytes released from the bone marrow due to the stimulation of increased erythropoietin (30). As it is known, COVID-19 disease is hypoxic respiratory failure disease. Depending on the effect of insufficient oxygen on target cells, there may be more erythrocytes and more oxygen transport reflex in the circulation. We think that the increase in the \% Macro $\mathrm{R}$ value is associated with mortality.

\section{CONCLUSION}

There are many parameters associated with mortality and morbidity in COVID-19 disease. In critical COVID-19 patients who need to be treated in the intensive care unit, APACHE II, SAPS II score, platelet count, PDW, MPV and \%P LCR values from CBC parameters can provide information about the prognosis of the patient. Especially in non-anemic patients, the increase in \% Macro $\mathrm{R}$ value 
can be used as a new marker that can be associated with mortality. The small number of participants is a limiting factor for our study. The \%Macro R marker, which is used to investigate the etiology of anemia, should be investigated in more participants and different disease groups (especially diseases causing hypoxemia).

\section{ETHICAL DECLARATIONS}

Ethics Committee Approval: Approval for study was obtained from the Non-interventional Clinical Researchs Ethics Committee of Kastamonu University Faculty of Medicine (Date: 25/02/2021, Decision No: KAEK-2020143-38).

Informed Consent: Because the study was designed retrospectively, no written informed consent form was obtained from patients.

Referee Evaluation Process: Externally peer-reviewed.

Conflict of Interest Statement: The authors have no conflicts of interest to declare.

Financial Disclosure: The authors declared that this study has received no financial support.

Author Contributions: All of the authors declare that they have all participated in the design, execution, and analysis of the paper, and that they have approved the final version.

\section{REFERENCES}

1. Zhou P, Yang XL, Wang XG. A pneumonia outbreak associated with a new coronavirus of probable bat origin. Nature 2020; 579: 270-3.

2. World Health Organization; 2020. Coronavirus disease (COVID -2019) Situation Reports. Available from: https://www.who.int/ docs/default-source/coronaviruse/situation-reports/20200311sitrep-51-COVID-19.pdf?sfvrsn=1ba62e57_10 (Accessed on $3 / 11 / 2020$ ).

3. Murthy S, Archambault PM, Atique A, et al. Characteristics and outcomes of patients with COVID -19 admitted to hospital and intensive care in the first phase of the pandemic in Canada: a national cohort study. CMAJ Open 2021; 9: E181-8.

4. Estella Á, Garcia Garmendia JL, de la Fuente C, et al. Predictive factors of six-week mortality in critically ill patients with SARSCoV-2: A multicenter prospective study. Med Intensiva. 2021; S0210-5691: 00033-4.

5. Li H Luo S, Zhang Y, Xiao X, Liu H. Longitudinal chest CT features in severe/critical COVID-19 cases and the predictive value of the initial CT for mortality. J Inflamm Res 2021; 14: 1111-24.

6. Chen R, Sang L, Jiang M, et al. Longitudinal hematologic and immunologic variations associated with the progression of COVID-19 patients in China. J Allergy Clin Immunol 2020; 146: 89-100.

7. Qin C, Zhou L, Hu Z, et al. Dysregulation of immune response in patients with coronavirus 2019 (COVID-19) in Wuhan, China. Clin Infect Dis 2020; 71: 762-8.

8. Lanini S, Montaldo C, Nicastri E, et al. COVID-19 diseaseTemporal analyses of complete blood count parameters over course of illness, and relationship to patient demographics and management outcomes in survivors and non-survivors:
A longitudinal descriptive cohort study. PLoS One 2020; 15 : e0244129.

9. Ashorobi D, Munakomi S. Myelophthisic Anemia. (Updated 2021 May 1). In: StatPearls (Internet). Treasure Island (FL): StatPearls Publishing; 2021 Jan-. Available from: https://www.ncbi.nlm.nih. gov/books/NBK541103/

10. World Health Organization, 1968. Nutritional anaemias: report of a WHO scientific group (meeting held in Geneva from 13 to 17 March 1967).

11. Republic of Turkey Ministry of Health; Available from: (Accessed on $5 / 07 / 2021$ )

12. Grasselli G, Zangrillo A, Zanella A, et al. Baseline characteristics and outcomes of 1591 patients infected with SARS-CoV-2 admitted to ICUs of the Lombardy Region, Italy. JAMA 2020; 323: 1574-81.

13. Vogels Y, Pouwels S, van Oers J, Ramnarain D. Characteristics and risk factors associated with mortality in critically ill patients with COVID-19. Cureus 2021; 13: e14442.

14. Rapp JL, Tremblay D, Alpert N, et al. Red cell distribution width is associated with mortality in non-anemic patients with COVID-19. J Med Virol 2021; 93: 4130-2.

15. Kokoszka-Bargieł I, Cyprys P, Rutkowska K, Madowicz J, Knapik P. Intensive care unit admissions during the first 3 months of the COVID-19 pandemic in Poland: a single-center, cross-sectional study. Med Sci Monit 2020; 26: e926974.

16. Armstrong RA, Kane AD, Cook TM. Outcomes from intensive care in patients with COVID -19: a systematic review and metaanalysis of observational studies. Anaesthesia 2020; 75: 1340-9.

17. Williamson EJ, Walker AJ, Bhaskaran K, et al. Factors associated with COVID -19-related death using OpenSAFELY. Nature 2020; 584: 430-6.

18. Xie J, Wu W, Li S, et al. Clinical characteristics and outcomes of critically ill patients with novel coronavirus infectious disease (COVID-19) in China: a retrospective multicenter study. Intensive Care Med 2020; 46: 1863-72.

19. Qu R, Hu L, Ling Y, et al. C-reactive protein concentration as a risk predictor of mortality in intensive care unit: a multicenter, prospective, observational study. BMC Anesthesiol 2020; 20: 292.

20.Larcher R, Besnard N, Akouz A, et al. Admission high-sensitive cardiac troponin $t$ level increase is independently associated with higher mortality in critically ill patients with COVID-19: a multicenter study. J Clin Med 2021; 10: 1656.

21.Duclos G, Bazalguette F, Allaouchiche B, et al. Can thoracic ultrasound on admission predict the outcome of critically ill patients with SARS-CoV-2? a French multi-centric ancillary retrospective study. Adv Ther 2021; 38: 2599-612.

22. Mahat RK, Panda S, Rathore V, Swain S, Yadav L, Sah SP. The dynamics of inflammatory markers in coronavirus disease-2019 (COVID -19) patients: A systematic review and meta-analysis. Clin Epidemiol Glob Health 2021; 11: 100727.

23. Adam EH, Zacharowski K, Miesbach W. A comprehensive assessment of the coagulation profile in critically ill COVID-19 patients. Thromb Res 2020; 194: 42-4.

24. Horton S, Fleming KA, Kuti M, et al. The top 25 laboratory tests by volume and revenue in five different countries. Am J Clin Pathol 2019; 151: 446-51.

25. Mousavi SA, Rad S, Rostami T, et al. Hematologic predictors of mortality in hospitalized patients with COVID -19: a comparative study. Hematology 2020; 25: 383-8.

26. Ouyang SM, Zhu HQ, Xie YN, et al. Temporal changes in laboratory markers of survivors and non-survivors of adult inpatients with COVID-19. BMC Infect Dis 2020; 20: 952.

27. Güçlü E, Kocayiğit H, Okan HD, et al. Effect of COVID -19 on platelet count and its indices. Rev Assoc Med Bras (1992) 2020; 66: 11227. 
28. Bommenahalli Gowda S, Gosavi S, Ananda Rao A, et al. Prognosis of COVID-19: Red cell distribution width, platelet distribution width, and C-reactive protein. Cureus 2021; 13: e13078.

29. Lee JJ, Montazerin SM, Jamil A, et al. Association between red blood cell distribution width and mortality and severity among patients with COVID-19: A systematic review and meta-analysis. J Med Virol 2021; 93: 2513-22.

30. Horne BD, Muhlestein JB, Bennett ST, et al. Extreme erythrocyte macrocytic and microcytic percentages are highly predictive of morbidity and mortality. JCI Insight 2018; 3: e120183.

31.Brecher G, Stohlman F jr. Reticulocyte size and erythropoietic stimulation. Proc Soc Exp Biol Med 1961; 107: 887-91. 